\title{
Effects of Sodium Glucose Co-Transporter 2 Inhibitors in Type 1 Diabetes Mellitus on Body Composition and Glucose Variabilities: Single-Arm, Exploratory Trial
}

\author{
Yusuke Baba $\cdot$ Ryoichi Ishibashi (D) - Atsushi Takasaki · Chiho Ito $\cdot$ Atsuko Watanabe \\ Megumi Tokita • Miwako Meguro • Tomomi Harama - Kiichi Hirayama • Tetsuya Yamamoto • \\ Susumu Nakamura · Masaya Koshizaka · Yoshiro Maezawa · Daigaku Uchida · Fumitaka Okajima
}

Received: January 25, 2021 / Accepted: March 2, 2021 / Published online: March 18, 2021

(C) The Author(s) 2021

\section{ABSTRACT}

Introduction: Sodium glucose co-transporter 2 (SGLT2) inhibitors are widely used in the management of type 2 diabetes mellitus; they prevent cardiovascular events and reduce fat mass. However, little is known about the effects of SGLT2 inhibitors on type 1 diabetes mellitus as an adjuvant to insulin therapy. Therefore, we aimed to elucidate the effects of SGLT2

Y. Baba - R. Ishibashi $(\bowtie) \cdot$ C. Ito - A. Watanabe .

M. Tokita · M. Meguro · T. Harama · K. Hirayama .

T. Yamamoto $\cdot$ S. Nakamura $\cdot$ D. Uchida

Department of Medicine, Division of Diabetes,

Endocrinology and Metabolism, Kimitsu Chuo

Hospital, Chiba, Japan

e-mail: ishibashi-cib@umin.net

R. Ishibashi · M. Koshizaka - Y. Maezawa Department of Endocrinology, Hematology and Gerontology, Chiba University Graduate School of Medicine, Chiba, Japan

\section{A. Takasaki}

Department of Diabetes, Endocrinology and

Metabolism, Japanese Red Cross Narita Hospital, Chiba, Japan

M. Koshizaka · Y. Maezawa

Division of Diabetes, Metabolism and

Endocrinology, Chiba University Hospital, Chiba, Japan

F. Okajima

Department of Diabetes, Endocrinology and

Metabolism, Nippon Medical School, Chiba

Hokusoh Hospital, Chiba, Japan inhibitors on body composition of patients with type 1 diabetes mellitus and assess blood glucose variability.

Methods: A single-center, single-arm, prospective, interventional study was performed on Japanese patients with type 1 diabetes mellitus who were not administered SGLT2 inhibitors prior to this study. These patients were equipped with flash glucose monitoring (FGM) and administered ipragliflozin $50 \mathrm{mg}$ daily. Body composition was evaluated using bioelectrical impedance analysis, and glycemic variabilities were assessed using FGM before and after SGLT2 inhibitor treatment.

Results: After 52 weeks of treatment, the total fat mass tended to be reduced $(-9.10 \%$ from baseline, $P=0.098$ ). In addition, skeletal muscle mass also decreased $(-2.98 \%$ from baseline, $P=0.023)$. Although the basal insulin dose was reduced, SGLT2 inhibitors decreased HbA1c levels. FGM revealed that glycemic variabilities were also reduced, and time within the target glucose range increased $(51.7 \%$ vs. $62.5 \%, P=0.004)$.

Conclusion: SGLT2 inhibitors have beneficial effects on glycemic variabilities and fat mass reductions in patients with type 1 diabetes mellitus. However, loss of skeletal muscle is a major concern; therefore, caution is required when using SGLT2 inhibitors in lean patients with type 1 diabetes mellitus.

Trial registration: University Hospital Medical Information Network Clinical Trial Registry (UMIN000042407). 
Keywords: Body composition; $\quad$ SGLT2 inhibitor; Type 1 diabetes mellitus

\section{Key Summary Points}

\section{Why carry out this study}

Sodium glucose co-transporter 2 (SGLT2) inhibitors have been widely studied and used for treating type 2 diabetes mellitus, but little is known about the effects of SGLT2 inhibitors on type 1 diabetes mellitus.

We aimed to determine whether SGLT2 inhibitors change body composition and blood glucose variability.

\section{What was learned from the study?}

SGLT2 inhibitors stabilized glycemic variabilities and tended to decrease fat mass; however, we observed a loss in skeletal muscle.

Although SGLT2 inhibitors are novel agents for type 1 diabetes, careful use of SGLT2 inhibitors must be ensured for lean patients with type 1 diabetes.

\section{DIGITAL FEATURES}

This article is published with digital features, including summary slide, to facilitate understanding of the article. To view digital features for this article go to https://doi.org/10.6084/ m9.figshare.14123996.

\section{INTRODUCTION}

The goal of diabetes mellitus management is to prevent complications based on optimal glucose control. However, this is challenging for patients with type 1 diabetes mellitus because of their large glucose variability. Type 1 diabetes mellitus is a heterogeneous disorder characterized by the destruction of pancreatic beta cells; therefore, insulin injection is the main form of therapy. However, the body mass index (BMI) of patients with type 1 diabetes mellitus has increased in recent years [1], and insulin resistance could be associated with the pathogenesis of type 1 diabetes mellitus. Sodium glucose co-transporter 2 (SGLT2) inhibitors are widely used in patients with type 2 diabetes mellitus to increase urinary glucose secretion, which reduces body weight and prevents cardiovascular diseases [2-4]. Recently, SGLT2 inhibitors have been used to manage patients with type 1 diabetes mellitus to decrease their body weight, HbA1c levels, and total daily insulin dose [5], becoming a new therapeutic option.

In contrast to the aforementioned advantages of SGLT2 inhibitors, there are some concerns about changes in body composition, especially those of muscles and bones. The reduction of muscle mass leads to sarcopenia, decreases the quality of life, and increases mortality. Although some studies have reported a relationship between SGLT2 inhibitors and muscle mass, the results are conflicting [6-9]. Moreover, the effect of SGLT2 inhibitors on bone has not been fully investigated. The Canagliflozin Cardiovascular Assessment Study program, one of the major trials of SGLT2 inhibitors, showed that canagliflozin increased the risk of bone fractures [4]. In contrast, another canagliflozin trial, the Canagliflozin and Renal Events in Diabetes with Established Nephropathy Clinical Evaluation trial, did not show any increase in fracture risk [10]. These results indicate that further studies are needed to clarify these effects on the body. Moreover, these trials were performed on patients with type 2 diabetes mellitus; therefore, the effects on patients with type 1 diabetes mellitus are still unknown.

In this study, we aimed to elucidate the effects of SGLT2 inhibitors on the body composition of patients with type 1 diabetes mellitus. We also assessed blood glucose variability using flash glucose monitoring (FGM), before and after the administration of the SGLT2 inhibitor. 


\section{METHODS}

\section{Study Design}

This study was a 52-week single-center, openlabel, single-arm interventional study. Japanese outpatients with type 1 diabetes mellitus who visited Kimitsu Chuo Hospital were enrolled in the study. These patients were also enrolled in the satisfaction survey described as before [11]. The study was performed in full compliance with the Declaration of Helsinki, approved by the appropriate ethics review board of Kimitsu Chuo Hospital (approval number 446 and 521), and registered at the University Hospital Medical Information Network Clinical Trial Registry (UMIN000042407). The study period was from December 2018 to August 2020. The participants were aged 20-80 years, with HbA1c levels of $6.5-10.0 \%$ and BMI of at least $18.5 \mathrm{~kg} / \mathrm{m}^{2}$, and were diagnosed with type 1 diabetes according to the diabetes diagnostic criteria. All participants provided written informed consent. Patients who did not agree to participate in the study or who were not deemed to be indicated for SGLT2 inhibitor administration by the attending physician were excluded. Since, this study was conducted at a single facility, the number of participants was limited; therefore, the maximum number of participants was set as the recruitment target.

The participants received a $50 \mathrm{mg}$ daily dose of ipragliflozin, and their insulin dose was reduced by $10-20 \%$ prior to the administration of the ipragliflozin to avoid hypoglycemia. The adjustment of the insulin dose was entrusted to the patients during the study period. Before commencing the administration of ipragliflozin, the attending physicians and nurses explained to the patients, according to the STICH protocol, how to prevent diabetic ketoacidosis [12]. Other regimens such as exercise, diet, and other medication were maintained.

The primary outcome was any change in the body composition measured by bioelectrical impedance analysis (BIA) using InBody S10 (Inbody Co, Ltd., Seoul, Korea) 52 weeks after ipragliflozin administration. The evaluation time points were weeks 0 (baseline), 12, and 52 . Secondary outcomes included changes in the body weight, blood pressure, fasting plasma glucose, HbA1c, alanine aminotransferase (AST), aspartate aminotransferase (ALT), creatinine, urine albumin creatinine ratio, insulin doses, and glycemic variability. Safety was analyzed by recording all adverse events observed during the study.

To analyze glycemic variability, the participants were supplied with an FGM (Abbott Freestyle Libre) to monitor their glucose trends for at least a month before the administration of the ipragliflozin. Data obtained were analyzed using EasyGV (Oxford University, Oxford, UK) to calculate glycemic variability.

\section{Statistical Analysis}

Basic statistics were calculated at each measuring point, and changes from baseline to each visit were evaluated using the Dunnett's test when the Shapiro-Wilk test for normality was met; otherwise, the Mann-Whitney test was performed. Correlations were evaluated with Pearson's correlation coefficient. All $P$ values less than 0.05 were considered statistically significant. All statistical analyses were carried out using GraphPad Prism 8.4.2 (GraphPad Software Inc., San Diego, CA, USA).

\section{RESULTS}

In total, 24 patients with type 1 diabetes mellitus were recruited and treated with $50 \mathrm{mg}$ of ipragliflozin; however, 4 patients did not continue with the ipragliflozin for the complete duration of 52 weeks (1 died from cancer, 1 could not continue because of the progression of ulcerative colitis, 1 could not continue because of frequent urination, and 1 withdrew their consent; Fig. 1). Efficacy analyses were performed on the remaining 20 patients. Regarding the body component analysis, 2 patients were excluded owing to the use of diuretics. Patient characteristics are presented in Table 1. 


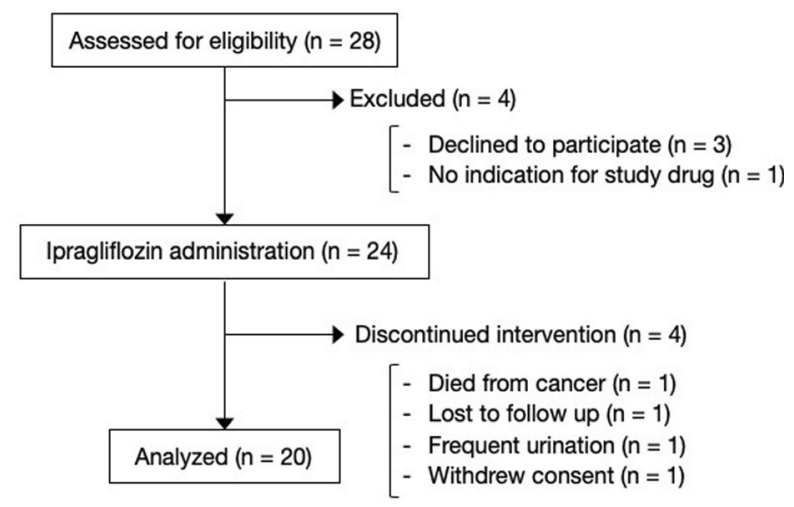

Fig. 1 Overview of the trial. A total of 28 patients were assessed for eligibility and 24 patients were enrolled. Efficacy analyses were performed on the 20 patients administrated ipragliflozin for 52 weeks

\section{Changes in Body Composition}

Administration of the SGLT2 inhibitor dramatically changed the body composition at 12 and 52 weeks (Table 2). Body weight decreased by $1.89 \mathrm{~kg}(95 \%$ confidence interval -3.11 to $-0.66 \mathrm{~kg}, P<0.001)$ at 12 weeks and $2.88 \mathrm{~kg}$ (95\% confidence interval -5.01 to -0.68 , $P=0.011)$ at 52 weeks from baseline. Although this change was mainly due to the reduction in total fat mass, the difference was not significant. In contrast, the skeletal muscle mass tended to decrease at both 12 and 52 weeks (by $0.66 \mathrm{~kg}$ and $0.76 \mathrm{~kg}$, respectively). Thus, the skeletal muscle mass index significantly decreased $\left(-0.25 \mathrm{~kg} / \mathrm{m}^{2}\right.$ at 12 weeks and $-0.31 \mathrm{~kg} / \mathrm{m}^{2}$ at 52 weeks). Age tended to be negatively correlated with skeletal muscle mass $(r=-0.452$, $P=0.060$; Fig. 2a), but not with total fat mass ( $r=-0.002 \quad P=0.992$; Fig. $2 b)$ difference at 52 weeks. The change in skeletal muscle also correlated with the change in bolus insulin after administering SGLT2 inhibitor for 52 weeks (Fig. 2c). BMI was positively correlated with skeletal muscle mass index at baseline $(r=0.567, P=0.014$; Fig. 2d).

A slight, but not significant, difference was observed in bone mineral content as well. The reduction in bone mineral content correlated well with the change in total body water but not with the change in total fat mass (Fig. 3).
Table 1 Basal characteristics of the participants

\begin{tabular}{ll}
\hline Characteristic $(\boldsymbol{n}=\mathbf{2 0})$ & \\
\hline Sex, male $(n)$ & $52.9 \pm 13.8$ \\
Age (years) & $64.8 \pm 12.6$ \\
Body weight $(\mathrm{kg})$ & $24.4 \pm 3.1$ \\
BMI $\left(\mathrm{kg} / \mathrm{m}^{2}\right)$ & $7.79 \pm 0.94$ \\
HbAlc (\%) & $165.7 \pm 61.8$ \\
Fasting plasma glucose (mg/dL) & $0.32 \pm 0.42$ \\
C-peptide (ng/mL) & $73.3 \pm 22.5$ \\
eGFR (mL/min/1.73 m $\left.{ }^{2}\right)$ & $14.0 \pm 12.6$ \\
Duration of diabetes (years) & \\
Coexisting diseases & 40.0 \\
Hypertension (\%) & 90.0 \\
Dyslipidemia (\%) & \\
Diabetic complications & 30.0 \\
Diabetic nephropathy (\%) & 25.0 \\
Diabetic retinopathy (\%) & 20.0 \\
Diabetic neuropathy (\%) & 10.0 \\
Using diuretics (\%) & 0 \\
Osteoporosis with medication (\%) & 10.0 \\
Insulin pump user (\%) & \\
\hline
\end{tabular}

$e G F R$ estimated glomerular filtration rate

Data show number, mean $\pm S D$, or percentage

\section{Changes in Clinical Parameters}

The changes in clinical parameters are shown in Table 3. BMI decreased significantly after 12 weeks of intervention relative to that at baseline $\left(24.3 \pm 3.1\right.$ to $23.6 \pm 3.0 \mathrm{~kg} / \mathrm{m}^{2}$, $P=0.001)$, and this change was sustained at 52 weeks $\left(23.3 \pm 3.0 \mathrm{~kg} / \mathrm{m}^{2}, \quad P=0.006\right.$ [compared to baseline]) as well. The HbA1c and plasma glucose levels also showed a decrease at 12 weeks but not at 52 weeks (HbA1c: $7.79 \pm 0.94 \%, \quad 7.30 \pm 0.86 \% \quad(P=0.002)$, $7.55 \pm 0.67 \% \quad(P=0.271) ; \quad$ plasma glucose: $170.4 \pm 66.6 \mathrm{mg} / \mathrm{dL}, \quad 148.2 \pm 40.8 \mathrm{mg} / \mathrm{dL}$ 
Table 2 Changes in the body components

\begin{tabular}{|c|c|c|c|}
\hline & Baseline & Week 12 & Week 52 \\
\hline \multicolumn{4}{|l|}{ Body weight $(\mathrm{kg})$} \\
\hline Observed value & $64.8(58.2$ to 71.4$)$ & $62.9(56.3$ to 69.4$)$ & $61.9(55.1$ to 68.7$)$ \\
\hline Difference from the baseline & - & $-1.89(-3.11 \text { to }-0.66)^{* *}$ & $-2.88(-5.01 \text { to }-0.68)^{*}$ \\
\hline $\begin{array}{l}\text { Reduction rate from the } \\
\text { baseline }(\%)\end{array}$ & - & $-2.88(-4.93 \text { to }-0.83)^{* *}$ & $\begin{array}{l}-4.49(-7.76 \text { to }- \\
1.22)^{* *}\end{array}$ \\
\hline \multicolumn{4}{|l|}{ BMI $\left(\mathrm{kg} / \mathrm{m}^{2}\right)$} \\
\hline Observed value & $24.5(22.9$ to 26.0$)$ & $23.7(22.2$ to 25.2$)$ & $23.3(21.8$ to 24.9$)$ \\
\hline Difference from the baseline & - & $-0.71(-1.20 \text { to }-0.23)^{* *}$ & $\begin{array}{l}-1.13(-1.97 \text { to }- \\
0.29)^{* *}\end{array}$ \\
\hline $\begin{array}{l}\text { Reduction rate from the } \\
\text { baseline (\%) }\end{array}$ & - & $-2.88(-4.93 \text { to }-0.83)^{* *}$ & $\begin{array}{l}-4.49(-7.76 \text { to }- \\
1.22)^{* *}\end{array}$ \\
\hline \multicolumn{4}{|l|}{ Total fat mass (kg) } \\
\hline Observed value & $18.1(15.0$ to 21.2$)$ & $17.1(13.3$ to 20.9$)$ & $16.4(12.9$ to 19.9$)$ \\
\hline Difference from the baseline & - & $-0.84(-2.61$ to 0.95$)$ & $-1.64(-3.61$ to -0.32$)$ \\
\hline $\begin{array}{l}\text { Reduction rate from the } \\
\text { baseline (\%) }\end{array}$ & - & $-5.35(-14.9$ to 4.14$)$ & $-9.10(-19.7$ to 1.54$)$ \\
\hline \multicolumn{4}{|l|}{ Skeletal muscle mass (kg) } \\
\hline Observed value & $25.6(22.5$ to 28.8$)$ & $24.6(21.7$ to 27.6$)$ & $24.9(21.8$ to 28.0$)$ \\
\hline Difference from the baseline & - & $-0.66(-1.33$ to 0.01$)$ & $-0.76(-1.47 \text { to }-0.04)^{*}$ \\
\hline $\begin{array}{l}\text { Reduction rate from the } \\
\text { baseline }(\%)\end{array}$ & - & $-2.30(-4.57 \text { to }-0.02)^{*}$ & $-2.98(-5.54 \text { to }-0.40)^{*}$ \\
\hline \multicolumn{4}{|l|}{ Bone mineral content $(\mathrm{kg})$} \\
\hline Observed value & $2.59(2.32$ to 2.86$)$ & $2.49(2.26$ to 2.72$)$ & $2.55(2.30$ to 2.80$)$ \\
\hline Difference from the baseline & - & $-0.065(-0.178$ to 0.049$)$ & $-0.040(-0.133$ to 0.053$)$ \\
\hline $\begin{array}{l}\text { Reduction rate from the } \\
\text { baseline }(\%)\end{array}$ & - & $-1.84(-5.59$ to 1.90$)$ & $-1.15(-4.38$ to 2.07$)$ \\
\hline \multicolumn{4}{|l|}{ Total body water $(\mathrm{kg})$} \\
\hline Observed value & $34.4(30.6$ to 38.2$)$ & $33.1(29.4$ to 36.7$)$ & $33.5(29.8$ to 37.2$)$ \\
\hline Difference from the baseline & - & $-0.92(-1.78 \text { to }-0.06)^{*}$ & $-0.94(-1.78 \text { to }-0.10)^{*}$ \\
\hline $\begin{array}{l}\text { Reduction rate from the } \\
\text { baseline (\%) }\end{array}$ & - & $-2.46(-4.63 \text { to }-0.29)^{*}$ & $\begin{array}{l}-2.67(-4.86 \text { to }- \\
0.49)^{* *}\end{array}$ \\
\hline \multicolumn{4}{|l|}{ ECW/TBW } \\
\hline Observed value & $\begin{array}{l}0.3853(0.3814 \text { to } \\
0.3893)\end{array}$ & $0.3831(0.3793$ to 0.3869$)$ & $0.3851(0.3808$ to 0.3893$)$ \\
\hline
\end{tabular}


Table 2 continued

\begin{tabular}{|c|c|c|c|}
\hline & Baseline & Week 12 & Week 52 \\
\hline Difference from the baseline & - & $\begin{array}{l}-0.0024(-0.0044 \text { to }- \\
0.0004)^{*}\end{array}$ & $\begin{array}{l}-0.0003(-0.0031 \text { to } \\
0.0025)\end{array}$ \\
\hline $\begin{array}{l}\text { Reduction rate from the } \\
\text { baseline (\%) }\end{array}$ & - & $-0.618(-1.138 \text { to }-0.098)^{*}$ & $-0.068(-0.795$ to 0.660$)$ \\
\hline \multicolumn{4}{|c|}{ Skeletal muscle mass index $\left(\mathrm{kg} / \mathrm{m}^{2}\right)$} \\
\hline Observed value & $7.26(6.71$ to 7.80$)$ & $6.97(6.41$ to 7.51$)$ & $6.95(6.41$ to 7.49$)$ \\
\hline Difference from the baseline & - & $-0.25(-0.40 \text { to }-0.10)^{* *}$ & $\begin{array}{l}-0.31(-0.46 \text { to }- \\
0.17)^{* * *}\end{array}$ \\
\hline $\begin{array}{l}\text { Reduction rate from the } \\
\text { baseline (\%) }\end{array}$ & - & $-3.40(-5.34 \text { to }-1.45)^{* *}$ & $\begin{array}{l}-4.31(-6.26 \text { to }- \\
2.38)^{* * *}\end{array}$ \\
\hline
\end{tabular}

$E C W / T B W$ extracellular water/total body water

Data are presented as mean (95\% confidence interval). ${ }^{* * *} P<0.001,{ }^{* *} P<0.01,{ }^{*} P<0.05$

$(P=0.288), \quad 177.1 \pm 51.7 \mathrm{mg} / \mathrm{dL} \quad(P=0.619) ;$ each value is shown at 0 week, 12 weeks, and 52 weeks and compared it to those at baseline $(P$ value $)$. The reduction in HbA1c level did not correlate with the reduction of body weight at both $12(r=-0.008, \quad P=0.972)$ and 52 $(r=0.056, \quad P=0.816)$ weeks. Insulin doses, especially the basal insulin dose, decreased after the administration of the SGLT2 inhibitor (total insulin: $42.2 \pm 14.5$ to $37.8 \pm 15.3 \mathrm{unit} /$ day at 12 weeks, $P=0.060$, to $40.1 \pm 15.3$ unit/day at 52 weeks, $P=0.404$; basal insulin: $15.0 \pm 7.2$ to $13.8 \pm 7.1 \mathrm{unit} / \mathrm{day}$ at 12 weeks, $P=0.089$, to $12.4 \pm 7.0$ units/day at 52 weeks, $P=0.002$; bolus insulin: $27.2 \pm 8.8$ to $23.9 \pm 10.5$ unit/day at 12 weeks, $P=0.064$, to $27.6 \pm 11.0$ unit/day at 52 weeks, $P=0.956$ ). Liver and renal functions did not differ from baseline measurements.

\section{Changes in Glycemic Variability}

The changes in glycemic variability analyzed by FGM are summarized in Fig. 4. The mean glucose decreased after 12 weeks of SGLT2 inhibitor administration $\quad(170.1 \mathrm{mg} / \mathrm{dL} \quad$ vs. $152.7 \mathrm{mg} / \mathrm{dL}, \quad P=0.024)$. The glycemic variability, represented by standard deviation (SD) and mean amplitude of glucose excursion (MAGE), also decreased with SGLT2 inhibitor administration (SD $73.2 \mathrm{mg} / \mathrm{dL}$ vs. $66.1 \mathrm{mg} / \mathrm{dL}$, $P<0.001$; MAGE $173.4 \mathrm{mg} / \mathrm{dL}$ vs. $155.1 \mathrm{mg} / \mathrm{dL}$, $P<0.001)$. These changes were sustained for the 52 weeks of SGLT2 inhibitor treatment. Stabilization of glycemic variability was also observed in the FGM data. The SGLT2 inhibitor treatment increased time in range (TIR) and decreased time above range (TAR) after 12 weeks of SGLT2 inhibitor administration (TIR 51.7\% vs. $58.9 \%, P=0.025$; TAR $40.3 \%$ vs. $30.7 \%$, $P=0.015)$. Although time below range (TBR) increased after 12 weeks of treatment $(8.0 \%$ vs. $10.4 \%, P=0.031)$, there was no difference after 52 weeks of treatment $(8.0 \%$ vs. $7.9 \%$, $P=0.365$ ).

\section{Adverse Events}

We recorded one case of severe hypoglycemia and one case of diabetic ketoacidosis during the study period. Diabetic ketoacidosis was caused by an obstruction of the insulin pump and recovered by insulin injection. Other adverse events are shown in Table 4. 
a

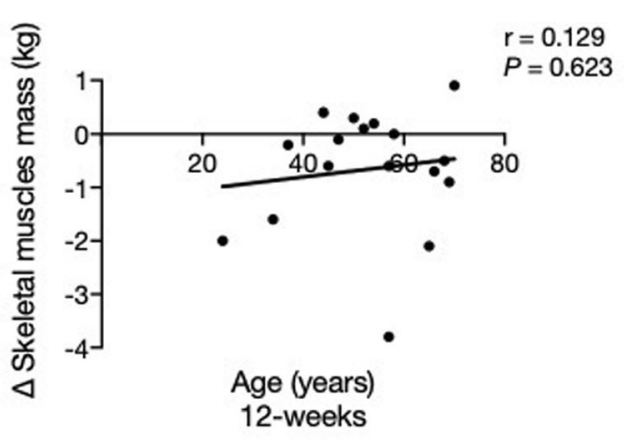

b

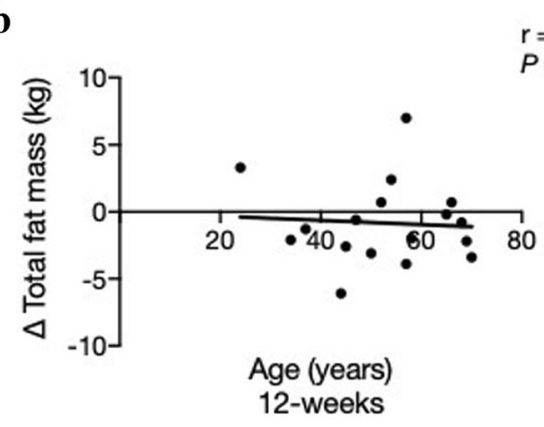

c

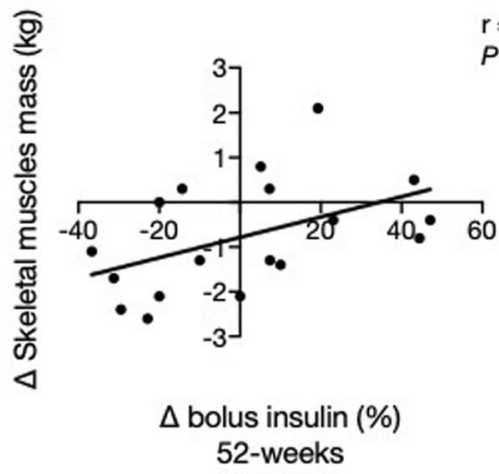

Fig. 2 Correlation between skeletal muscle and total fat mass. a Correlations between age and the changes in skeletal muscle mass at 12 and 52 weeks. b Correlations between age and the changes in total fat mass at 12 and 52 weeks. c Correlations between the change of bolus insulin and that of skeletal muscle mass. $\mathbf{d}$ Correlations

\section{DISCUSSION}

SGLT2 inhibitors are widely used to treat obese patients with type 2 diabetes mellitus, owing to the weight reduction effect of SGLT2. Of late, body weight management in type 1 diabetes mellitus has become an important health issue.
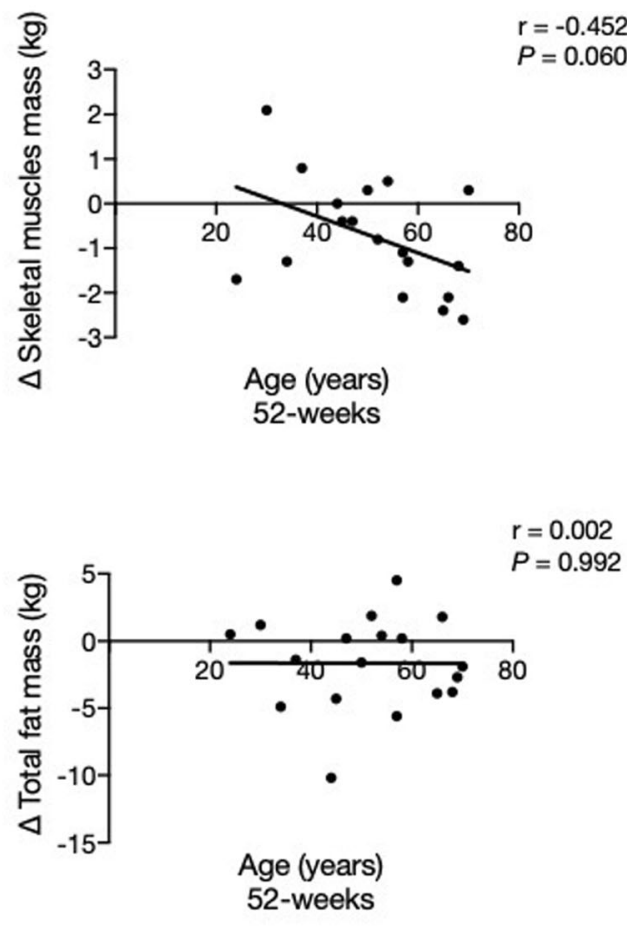

d

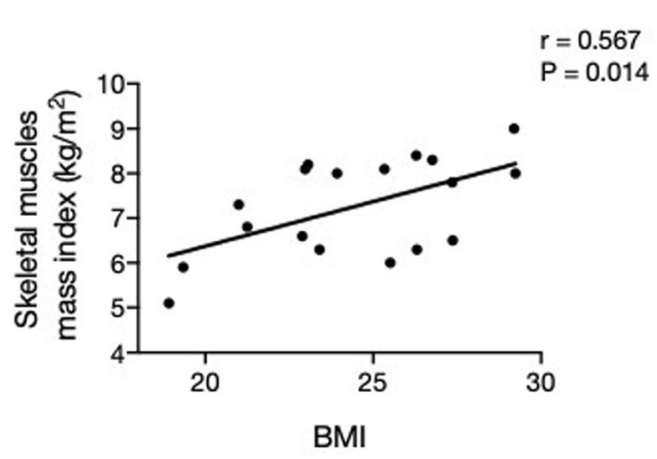

between BMI and skeletal muscle mass index at baseline. Pearson's correlation coefficient was used in each case. Line shows simple linear regressions

Insulin therapy is essential for patients with type 1 diabetes mellitus; however, a gain in body weight is a major side effect, which is of concern. SGLT2 inhibitors excrete blood glucose into the urine, thereby promoting energy loss and body weight reduction. Furthermore, they stimulate the absorption of phosphate and 


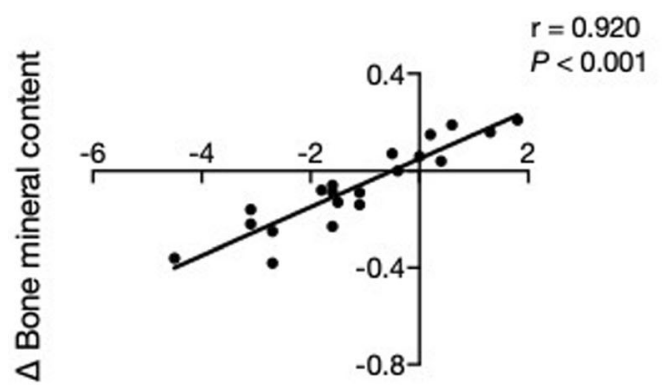

$\Delta$ Total body water

52-weeks

Fig. 3 Correlation of the changes in bone mineral content and parameters of other body components. Scatter plots using differences from the baseline of total body water, total fat mass, and bone mineral content after a 52 -week treatment with sodium glucose co-transporter 2 inhibitors.

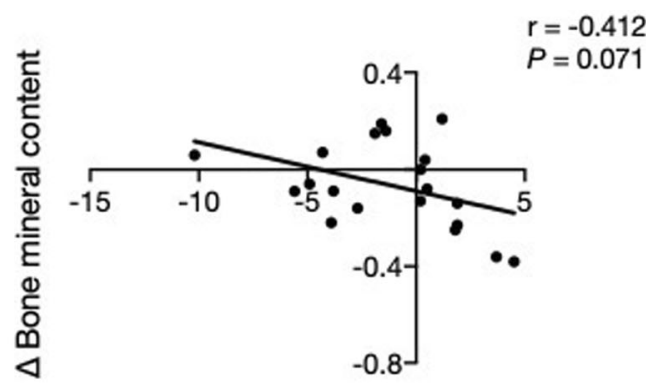

$\Delta$ Total fat mass

52-weeks

Pearson's correlation coefficient was used in each case. Line shows simple linear regressions

Table 3 Changes in the clinical parameters

\begin{tabular}{|c|c|c|c|c|c|}
\hline & 0 week & 12 weeks & 52 weeks & $\begin{array}{l}P \text { value }(0 \text { vs. } \\
12 \text { weeks })\end{array}$ & $\begin{array}{l}P \text { value }(0 \text { vs. } \\
52 \text { weeks) }\end{array}$ \\
\hline BMI $\left(\mathrm{kg} / \mathrm{m}^{2}\right)$ & $24.3 \pm 3.1$ & $23.6 \pm 3.0$ & $23.3 \pm 3.0$ & 0.001 & 0.006 \\
\hline SBP $(\mathrm{mmHg})$ & $125.0 \pm 14.2$ & $122.5 \pm 13.0$ & $122.8 \pm 11.8$ & 0.626 & 0.729 \\
\hline DBP (mmHg) & $72.0 \pm 9.5$ & $68.5 \pm 12.3$ & $70.2 \pm 8.9$ & 0.236 & 0.566 \\
\hline FPG (mg/dL) & $170.4 \pm 66.6$ & $148.2 \pm 40.8$ & $177.1 \pm 51.7$ & 0.288 & 0.619 \\
\hline HbAlc (\%) & $7.79 \pm 0.94$ & $7.30 \pm 0.86$ & $7.55 \pm 0.67$ & 0.002 & 0.271 \\
\hline $\operatorname{AST}(\mathrm{U} / \mathrm{mL})$ & $20.2 \pm 5.7$ & $26.4 \pm 22.0$ & $25.3 \pm 17.7$ & 0.769 & 0.411 \\
\hline $\operatorname{ALT}(\mathrm{U} / \mathrm{mL})$ & $18.2 \pm 8.2$ & $18.4 \pm 7.1$ & $22.3 \pm 15.6$ & $>0.999$ & $>0.999$ \\
\hline Creatinine $(\mathrm{mg} / \mathrm{dL})$ & $0.93 \pm 0.53$ & $0.93 \pm 0.51$ & $0.91 \pm 0.49$ & $>0.999$ & $>0.999$ \\
\hline eGFR & $73.3 \pm 22.5$ & $73.4 \pm 23.4$ & $72.5 \pm 21.9$ & $>0.999$ & $>0.999$ \\
\hline UACR (mg/gCre) & $\begin{array}{l}13.4(6.2 \text { to } \\
33.6)\end{array}$ & $\begin{array}{l}10.2(7.2 \text { to } \\
21.9)\end{array}$ & $\begin{array}{l}9.5(6.2 \text { to } \\
31.9)\end{array}$ & 0.512 & 0.583 \\
\hline $\begin{array}{l}\text { Total insulin } \\
\text { (unit/day) }\end{array}$ & $42.2 \pm 14.5$ & $37.8 \pm 15.3$ & $40.1 \pm 15.3$ & 0.060 & 0.404 \\
\hline $\begin{array}{l}\text { Basal insulin } \\
\text { (unit/day) }\end{array}$ & $15.0 \pm 7.2$ & $13.8 \pm 7.1$ & $12.4 \pm 7.0$ & 0.089 & 0.002 \\
\hline $\begin{array}{l}\text { Bolus insulin } \\
\text { (unit/day) }\end{array}$ & $27.2 \pm 8.8$ & $23.9 \pm 10.5$ & $27.6 \pm 11.0$ & 0.064 & 0.956 \\
\hline
\end{tabular}

$S B P$ systolic blood pressure, $D B P$ diastolic blood pressure, $F P G$ fasting plasma glucose, $A S T$ alanine aminotransferase, $A L T$ aspartate aminotransferase, $e G F R$ estimated glomerular filtration rate, $U A C R$ urine albumin creatinine ratio All data are presented as mean $\pm \mathrm{SD}$, but $\mathrm{UACR}$ is median (interquartile range) 
lead to calcinuria [13]. In this study, body weight reduced rapidly after the administration of the SGLT2 inhibitor, and this reduction was sustained for a long time. This drug has diuretic effects; therefore, a body composition analysis showed a loss of total body water after 12 weeks of treatment. Interestingly, there were no remarkable changes in total body water between 12 and 52 weeks. This result further indicates that long-term changes in body weight are not caused by water loss. The ratio of extracellular water to total body water showed a few differences; hence, there was no measurement error of BIA regarding the change of water distribution. Body composition analysis also revealed that SGLT2 inhibitors decreased fat mass, muscle mass, and bone mineral content. When compared to baseline, the reduction ratio indicates that total fat mass is the dominant factor, which is affected by the use of SGLT2 inhibitors, indicating that this drug has the therapeutic potential to manage obese patients with type 1 diabetes mellitus.

Despite previously established advantages, there are potential risks to muscle and bone. Reportedly, SGLT2 inhibitors reduced muscle mass in type 2 diabetes mellitus [7, 14]. In our study involving patients with type 1 diabetes, the muscle volume decreased after treatment. The reduction ratio was smaller than the total mass, but this result suggests a potential risk for sarcopenia. The mechanism of fat mass
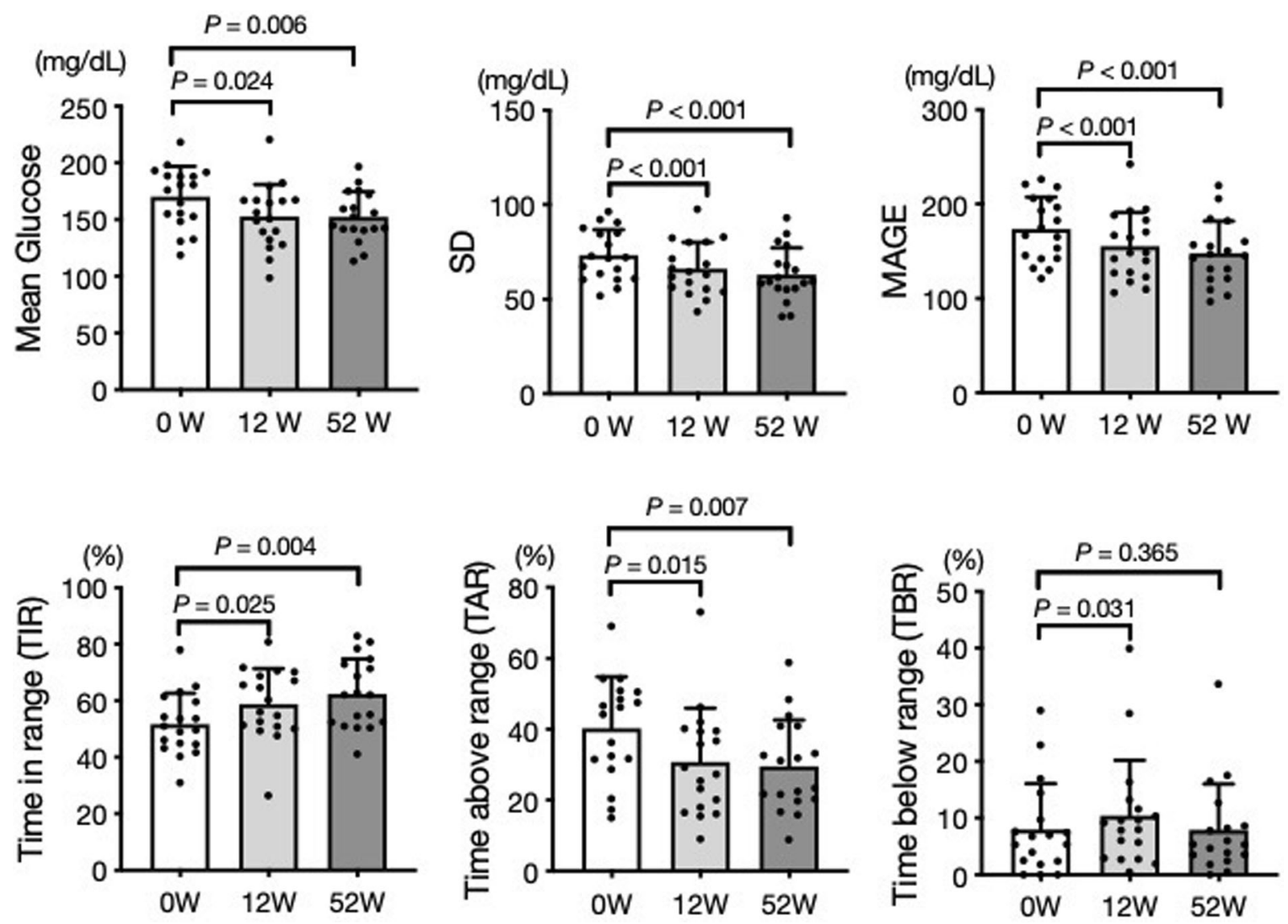

Fig. 4 Sodium glucose co-transporter 2 inhibitors (SGLT2) ameliorated glycemic variabilities. Changes from baseline in mean plasma glucose, standard deviation (SD), and mean amplitude of glucose excursion (MAGE) (upper), and percentage of time within or without target glucose range (lower) after 12 and 52 weeks of treatment with SGLT2 inhibitors. Dunnett's multiple comparisons tests were performed, and error bar shows SD 
reduction is believed to be the activation of gluconeogenesis. As a result, lipolysis and proteolysis can occur [15]. In addition, our study showed that age tended to be negatively correlated with the change in skeletal muscle mass, and patients with a lower BMI showed lower skeletal muscle mass index. Older adults have reduced protein synthesis and smaller satellite cells in muscles compared to younger adults [16]. Therefore, these drugs should be used cautiously in lean patients who lack sufficient muscle mass, such as older adults.

In a previous study, the bone resorption marker tartrate resistant acid phosphatase $5 b$ decreased after 24 weeks of SGLT2 inhibitor treatment [17]. Our findings also showed that bone mineral content calculated from BIA decreased after treatment. Although this change was similar to that of the total fat mass, the reduction in the bone mineral content recovered slightly at 52 weeks. Our regression analysis revealed that the reduction in bone mineral content was correlated with total body water loss. This suggests that bone mineral content may be affected by the excretion of calcium in urine. The effect of SGLT2 inhibitors on bone remains unclear, even with large clinical trials. Therefore, studies conducted for longer terms are required.

Table 4 Occurrence of adverse events

\begin{tabular}{ll}
\hline & $n(\%)$ \\
\hline $\begin{array}{l}\text { Severe hypoglycemia that needs help from a } \\
\text { third party }\end{array}$ & $1(4.2)$ \\
Diabetic ketoacidosis & $1(4.2)$ \\
Death from cancers & $1(4.2)$ \\
Positive urinary ketone body & $4(16.7)$ \\
AST $>3 \times$ upper limit of normal elevations & $1(4.2)$ \\
Urinary tract infections & $1(4.2)$ \\
Frequent urination & $5(20.8)$ \\
Poor physical condition & $3(12.5)$ \\
\hline
\end{tabular}

Safety analysis was performed in all patients included in this study $(n=24)$

$A S T$ alanine aminotransferase
In this study, administration of SGLT2 inhibitors also aided in reducing the basal insulin dose. Although we reduced the insulin dose by $10-20 \%$ after the administration of the SGLT2 inhibitor, the reduction in basal insulin levels was sustained for long durations and affected changes in body weight. However, the change in the dose of basal insulin level, the bolus insulin dose, did not differ at 52 weeks of SGLT2 inhibitor treatment. A previous meta-analysis showed that SGLT2 inhibitors reduced the doses of both basal and bolus insulin [18]. In our study, the insulin dose adjustments were entrusted to the patients, and the amount of food intake affected bolus insulin. Moreover, previous studies frequently used higher dose of SGLT2 inhibitors; however, our study used a lower dose of SGLT2 inhibitors. A previous study showed that a lower dose of SGLT2 inhibitors reduced basal insulin but not bolus insulin [19], which is consistent with our findings.

SGLT2 inhibitors adjust plasma glucose levels by inhibiting glucose reabsorption in the renal proximal tubule. Since insulin therapy does not have this advantage, a combination therapy can be useful to manage glucose variability in patients with type 1 diabetes mellitus. Our study showed that SGLT2 inhibitors decreased not only the mean plasma glucose but also SD and MAGE, which are indices of glucose variation, which leads to increased TIR. Previous research has shown that reductions of TIR are strongly associated with the risk of microvascular diabetic complications [20]. Therefore, the use of SGLT2 inhibitors in patients with type 1 diabetes mellitus would be beneficial not only for decreasing plasma glucose but also for preventing diabetic complications by reducing glucose variability. Although many antidiabetic agents potentially increase hypoglycemia, the dose of SGLT2 inhibitors did not increase TBR after 52 weeks of treatment in our study. One of the causes could be a decrease in insulin dose, especially basal insulin, at 52 weeks of SGLT2 inhibitor administration. In addition, SGLT2 inhibitors increase endogenous glucose production [21], reducing the possibility of hypoglycemia. 
This study has some limitations. First, this study had a small number of participants, raising concerns regarding selection bias. Second, dual-energy $\mathrm{x}$-ray absorptiometry, which is a standard method to evaluate bone density, was not used in this study. Although the BIA is a preferable method because it is noninvasive and economically feasible, it is limited by the variabilities in chemical composition, such as water, proteins, glycogen, and minerals [22]. Nonetheless, BIA has improved recently in terms of accuracy [23] and evaluation in bone [24] and is frequently used to analyze body composition. Third, this study used the FGM to evaluate glycemic variability. This device shows a glycemic trend when worn by patients and can be useful for self-management [25]. The FGM was supplied to the patients prior to SGLT2 inhibitor administration; however, its management by the patient may affect glucose variabilities. Finally, the study duration was limited to 52 weeks, which may not be sufficient to evaluate the long-term effects of SGLT2 inhibitors on bone. In addition, the occurrence of fractures was not assessed in this study. Therefore, further studies are needed to fully evaluate the effects of SGLT2 inhibitors on bone metabolism.

\section{CONCLUSION}

SGLT2 inhibitor treatment for type 1 diabetes mellitus was found to change body composition, especially by reducing total fat and skeletal muscle mass. In addition, it ameliorates glucose levels and variabilities. Our study also found that increasing TIR can prevent microvascular diabetic complications. SGLT2 inhibitors can be prescribed to patients with type 1 diabetes mellitus with caution.

\section{ACKNOWLEDGEMENTS}

The authors would like to thank all the participants of this study and all the clinical staff of Kimitsu Chuo Hospital for their assistance in the execution of this study. The authors thank
Chihiro Hiraga for their valuable assistance in preparing the manuscript.

Funding. No funding or sponsorship was received for this study or for publishing this article. The Rapid Service Fee was funded by the authors.

Medical Writing, Editorial and Other Assistance. This article has been edited for language by Editage, a division of Cactus Communications.

Authorship. All named authors meet the International Committee of Medical Journal Editors (ICMJE) criteria for authorship for this article, take responsibility for the integrity of the work as a whole, and have given their approval for this version to be published.

Disclosures. Ryoichi Ishibashi has received research funds from Astellas Pharma Inc., Amgen Astellas BioPharma K.K., Daiichi Sankyo Co. Ltd., Taisho Pharmaceutical Co. Ltd., Takeda Pharmaceutical Co., Ltd., MSD K.K., Boehringer Ingelheim Pharmaceuticals, Inc., and Mitsubishi Tanabe Pharma Corporation. Daigaku Uchida has received research funds from Astellas Pharma Inc. and MSD K.K. Yusuke Baba, Atsushi Takasaki, Chihiro Hiraga, Tomomi Harama, Kiichi Hirayama, Tetsuya Yamamoto, Susumu Nakamura, Masaya Koshizaka, Yoshiro Maezawa, and Fumitaka Okajima declare that they have no conflicts of interest. Ryoichi Ishibashi has received research funds from Astellas Pharma Inc., Amgen Astellas BioPharma K.K., Daiichi Sankyo Co. Ltd., Taisho Pharmaceutical Co. Ltd., Takeda Pharmaceutical Co., Ltd., MSD K.K., Boehringer Ingelheim Pharmaceuticals, Inc., and Mitsubishi Tanabe Pharma Corporation. Daigaku Uchida has received research funds from Astellas Pharma Inc. and MSD K.K. Yusuke Baba, Atsushi Takasaki, Chiho Ito, Atsuko Watanabe, Megumi Tokita, Miwako Meguro, Tomomi Harama, Kiichi Hirayama, Tetsuya Yamamoto, Susumu Nakamura, Masaya Koshizaka, Yoshiro Maezawa, Daigaku, and Fumitaka Okajima declare that they have no conflicts of interest. 
Compliance with Ethics Guidelines. This study and its protocols were approved by the institutional review board of Chiba University School of Medicine and Kimitsu Chuo Hospital according to the Ethical Guidelines for Medical and Health Research Involving Human Subjects issued by the Ministry of Health, Labour and Welfare of Japan. The study was conducted in accordance with the Declaration of Helsinki 1964 and its later amendments; the Ethical Guidelines for Medical and Health Research Involving Human Subjects issued by the Ministry of Health, Labour and Welfare of Japan; the Clinical Trials Act; and other current legal regulations in Japan. Written informed consent was obtained from all subjects after a full explanation of this study.

Data Availability. The datasets generated during and/or analyzed during the current study are not publicly available due to the lack of approval for data sharing from the institutional review board of Kimitsu Chuo Hospital.

Open Access. This article is licensed under a Creative Commons Attribution-NonCommercial 4.0 International License, which permits any non-commercial use, sharing, adaptation, distribution and reproduction in any medium or format, as long as you give appropriate credit to the original author(s) and the source, provide a link to the Creative Commons licence, and indicate if changes were made. The images or other third party material in this article are included in the article's Creative Commons licence, unless indicated otherwise in a credit line to the material. If material is not included in the article's Creative Commons licence and your intended use is not permitted by statutory regulation or exceeds the permitted use, you will need to obtain permission directly from the copyright holder. To view a copy of this licence, visit http://creativecommons.org/licenses/bync/4.0/.

\section{REFERENCES}

1. Edqvist J, Rawshani A, Adiels M, et al. BMI, mortality, and cardiovascular outcomes in type 1 diabetes: findings against an obesity paradox. Diabetes Care. 2019;42:1297-304.

2. Zinman B, Wanner C, Lachin JM, et al. Empagliflozin, cardiovascular outcomes, and mortality in type 2 diabetes. N Engl J Med. 2015;373:2117-28.

3. Wiviott SD, Raz I, Bonaca MP, et al. Dapagliflozin and cardiovascular outcomes in type 2 diabetes. N Engl J Med. 2019;380:347-57.

4. Neal B, Perkovic V, Mahaffey KW, et al. Canagliflozin and cardiovascular and renal events in type 2 diabetes. N Engl J Med. 2017;377:644-57.

5. Chen J, Fan F, Wang JY, et al. The efficacy and safety of SGLT2 inhibitors for adjunctive treatment of type 1 diabetes: a systematic review and metaanalysis. Sci Rep. 2017;7:44128.

6. Yamamoto C, Miyoshi H, Ono K, et al. Ipragliflozin effectively reduced visceral fat in Japanese patients with type 2 diabetes under adequate diet therapy. Endocr J. 2016;63:589-96.

7. Tsurutani Y, Nakai K, Inoue K, et al. Comparative study of the effects of ipragliflozin and sitagliptin on multiple metabolic variables in Japanese patients with type 2 diabetes: a multicentre, randomized, prospective, open-label, active-controlled study. Diabetes Obes Metab. 2018;20:2675-9.

8. Sugiyama S, Jinnouchi H, Kurinami N, et al. Dapagliflozin reduces fat mass without affecting muscle mass in type 2 diabetes. $\mathrm{J}$ Atheroscler Thromb. 2018;25:467-76.

9. Koshizaka M, Ishikawa K, Ishibashi R, et al. Comparing the effects of ipragliflozin versus metformin on visceral fat reduction and metabolic dysfunction in Japanese patients with type 2 diabetes treated with sitagliptin: a prospective, multicentre, openlabel, blinded-endpoint, randomized controlled study (PRIME-V study). Diabetes Obes Metab. 2019;21:1990-5.

10. Perkovic V, Jardine MJ, Neal B, et al. Canagliflozin and renal outcomes in type 2 diabetes and nephropathy. N Engl J Med. 2019;380:2295-306.

11. Ishibashi R, Baba $\mathrm{Y}$, Kakinuma $\mathrm{K}$, et al. Assessing patient satisfaction following sodium glucose cotransporter 2 inhibitor treatment for type 1 diabetes mellitus: a prospective study in Japan. Diabetes Ther. 2020. https://doi.org/10.1007/s13300020-00971-2. 
12. Garg SK, Peters AL, Buse JB, Danne T. Strategy for mitigating DKA risk in patients with type 1 diabetes on adjunctive treatment with SGLT inhibitors: a STICH protocol. Diabetes Technol Ther. 2018;20: $571-5$.

13. Edwards A, Bonny O. A model of calcium transport and regulation in the proximal tubule. Am J Physiol Renal Physiol. 2018;315:F942-53.

14. Sasaki T, Sugawara M, Fukuda M. Sodium-glucose cotransporter 2 inhibitor-induced changes in body composition and simultaneous changes in metabolic profile: 52-week prospective LIGHT (Luseogliflozin: the components of weight loss in Japanese patients with type 2 diabetes mellitus) study. J Diabetes Investig. 2019;10:108-17.

15. Yabe D, Nishikino R, Kaneko M, Iwasaki M, Seino Y. Short-term impacts of sodium/glucose co-transporter 2 inhibitors in Japanese clinical practice: considerations for their appropriate use to avoid serious adverse events. Expert Opin Drug Saf. $2015 ; 14: 795-800$.

16. McCormick R, Vasilaki A. Age-related changes in skeletal muscle: changes to life-style as a therapy. Biogerontology. 2018;19:519-36.

17. Koshizaka M, Ishikawa $K$, Ishibashi R, et al. Effects of ipragliflozin versus metformin in combination with sitagliptin on bone and muscle in Japanese patients with type 2 diabetes mellitus: subanalysis of a prospective, randomized, controlled study (PRIME-V study). J Diabetes Investig. 2020. https:// doi.org/10.1111/jdi.13340.

18. Yamada T, Shojima N, Noma H, Yamauchi T, Kadowaki T. Sodium-glucose co-transporter-2 inhibitors as add-on therapy to insulin for type 1 diabetes mellitus: systematic review and meta-analysis of randomized controlled trials. Diabetes Obes Metab. 2018;20:1755-61.
19. Henry RR, Thakkar P, Tong C, Polidori D, Alba M. Efficacy and safety of canagliflozin, a sodium-glucose cotransporter 2 inhibitor, as add-on to insulin in patients with type 1 diabetes. Diabetes Care. 2015;38:2258-65.

20. Beck RW, Bergenstal RM, Riddlesworth TD, et al. Validation of time in range as an outcome measure for diabetes clinical trials. Diabetes Care. 2019;42: 400-5.

21. Ferrannini E, Muscelli E, Frascerra S, et al. Metabolic response to sodium-glucose cotransporter 2 inhibition in type 2 diabetic patients. J Clin Invest. 2014;124:499-508.

22. Houtkooper LB, Going SB, Lohman TG, Roche AF, Van Loan M. Bioelectrical impedance estimation of fat-free body mass in children and youth: a crossvalidation study. J Appl Physiol. 1985;1992(72): 366-73.

23. Lee SY, Ahn S, Kim YJ, et al. Comparison between dual-energy X-ray absorptiometry and bioelectrical impedance analyses for accuracy in measuring whole body muscle mass and appendicular skeletal muscle mass. Nutrients. 2018;10:738.

24. Nickerson BS, Tinsley GM. Utilization of BIAderived bone mineral estimates exerts minimal impact on body fat estimates via multicompartment models in physically active adults. J Clin Densitom. 2018;21:541-9.

25. Haak T, Hanaire H, Ajjan R, Hermanns N, Riveline JP, Rayman G. Flash glucose-sensing technology as a replacement for blood glucose monitoring for the management of insulin-treated type 2 diabetes: a multicentre, open-label randomized controlled trial. Diabetes Ther. 2017;8:55-73. 